\title{
IMPLEMENTASI METODE DAKWAH ISLAM ALA NABI MUHAMMAD SAW DI INDONESIA
}

\author{
Enung Asmaya \\ Dosen Tetap Jurusan Dakwah STAIN Purwokerto
}

\begin{abstract}
Da'wa methodology is an important aspect in Islamic missionary. It formulates, create, and determine the most relevant methods of $d a$ 'wa in regards with the need of its audience ( mad'$^{\prime} u$ ). It is necessary for $d a$ 'wa to have a figure, actor, or agent who is really good at not only performing as an agent of da'wa but also functioning as a guide and consultant. The figure to be referred is Muhammad SAW, who was fully experienced with da'wawhen he lived in Makkah and Madinah. The characteristic of his da'wa was contextual, by which da'wa was implemented in respect to the prevalent social condition. This kind of methodology is the one that should be applied di Indonesia.
\end{abstract}

Keywords: Da'wa of Prophet Muhammad SAW, Mecca Period and Medina Period, da'wa of Indonesian Islam.

Abstrak: Metode Dakwah menjadi bagian yang penting dalam dakwah Islam. Melalui metodologi dakwah maka akan merumuskan, menemukan dan menentukan sistem dakwah Islam yang lebih relevan dengan kebutuhan masyarakat/ penerima dakwah/mad'u. Pentingnya metodologi ini membutuhkan figur/contoh/ aktor yang ahli dalam pelaksanaan dakwah Islam. Figur itu menjadi penuntun dan pertimbangan dalam pelaksanaan dakwah Islam. Figur tersebut adalah Muhammad SAW yang sarat dengan pengalaman dakwah Islam saat berada di Kota Mekkah dan Madinah. Karakteristik dakwah yang khas dari dakwah Muhammad SAW meniscayakan adanya ruang dan kesesuaian dengan konteks dakwah dimanapun termasuk konteks ke-Indonesia-an.

Kata-Kata Kunci: Dakwah Nabi Muhammad SAW, Periode Mekkah dan Periode Madinah, dan dakwah Islam ke-Indonesia-an.

\section{PENDAHULUAN}

Masyarakat Indonesia terdiri dari beragam suku, agama dan bahasa. Keberagaman itu sarat dengan perbedaan yang rawan menimbulkan konflik, pecah belah dan saling buruk sangka (pemberian labeling). ${ }^{1}$ Beragam kepentingan; militer ekonomi, sosial, budaya dan politik menambah warna dari masyarakat Indonesia yang perlu penanganan dan pengelolaan "cerdas" dari semua pihak. Luasnya wilayah Indonesia dari Sabang dan Merauke 
meliputi daratan, lautan, dan udara menambah kekhasan Indonesia yang multi etnik, suku, bahasa, agama/keyakinan dan partai politik.

Membangun peradaban dan kekuatan militer Indonesia diupayakan dapat menjaga keutuhan anak bangsa dengan terus berkordinasi, berkonsolidasi, dan berkomunikasi antara pemerintah pusat dan daerah. Kordinasi dimaksudkan dalam menyerap aspirasi, kebutuhan, problem, dan silaturahmi agar multietnik di daerah tidak menyebabkan lepas, hancur, dan porak poranda akibat masalah kecil menjadi besar dan mengakibatkan warga masyarakat "mutung" kepada pimpinan pusat bahkan melakukan suaka politik ke luar negeri atau memerdekakan diri dan mendirikan negara baru. ${ }^{2}$

Dalam konteks Indonesia, perhatian tersebut sesuai dengan pembukaan UUD 1945 "yakni mencerdaskan kehidupan bangsa dan memajukan kesejahteraan umum, perdamaian abadi dan keadilan sosial..." UndangUndang 1945 menjadi amanah perikehidupan dan perikebangsaan rakyat Indonesia yang mencerdaskan, memajukan, mendamaikan, dan berlaku adil untuk seluruh warga masyarakat, baik nasional atau internasional.

Menciptakan peradaban suatu bangsa berkonotasi menghasilkan cipta, karya, dan karsa masyarakat dalam melahirkan karya terbaiknya berupa perkembangan ilmu pengetahuan, lahirnya tokoh-tokoh besar bangsa, pemuda-pemudi yang membanggakan, banyaknya ide dan kegiatan yang positif dalam kemajuan bangsa, serta kepatuhan warga masyarakat akan nilai, norma dan aturan masyarakat yang telah disepakati. Terciptanya masyarakat yang adil, maju, sejahtera dan terhindar dari segala bentuk diskriminasi, penistaan, kebodohan, kemiskinan, ketidakadilan, dan perilaku curang. Perikehidupan lahir-batin yang sejahtera, gemah-ripah-repeh dan rapih, baldatun toyyibatun warobbun ghofur.

Dakwah Islam merupakan ajakan dan seruan agar manusia memiliki kebiasaan dan kepribadian yang baik; diri, keluarga dan masyarakat. ${ }^{3}$ Dakwah juga diartikan meninggalkan tradisi/kebiasaan/habit yang tidak sesuai dengan ajaran Islam, dan mengajak untuk mewujudkan tradisi/kebiasaan/habbit baru yang sesuai dengan nilai-nilai Islam. Dakwah Islam mengajarkan hidup aman, nyaman, selamat dan tenang. Menjauhkan diri dari kebodohan, memiliki ethos dan semangat dalam memajukan kesejahteraan umum, tidak melakukan kemunkaran, melakukan pemberdayaan masyarakat dan memberi kemahslahatan umat. Oleh karena itu, dakwah Islam menjadi relevan untuk "diusung" dan dilaksanakan dalam konteks ke- Indonesia-an.

Sebagai bangsa yang plural, baik dari aspek bahasa, suku, agama, politik, dan pendidikan, acapkali mudah dipicu konflik antar satu kelompok 
dan lainnya, melahirkan ketegangan, pertentangan, dan menjadi problem sosial yang menghambat kemajuan. Adanya heterogenitas memerlukan kearifan, pengetahuan, sikap, dan pemahaman sekaligus figur yang "piawai" dalam mengatasi dan menyelesaikan problem yang acapkali muncul. Figur menjadi model, pemandu, pembimbing, pengarah, dan pengatur dalam melaksanakan ide-ide, gagasan, dan pikiran guna diserap dan dilaksanakan semua umat. Melalui figur seseorang akan mudah menginternalisasi pengetahuan menjadi tindakan/perbuatan, terhindar dari miskomunikasi dan misunderstanding pesan yang disampaikan.

Dalam sejarah Islam, figur dakwah yang utama dan pertama adalah Muhammad SAW yang telah menjalankan dakwah Islam, meliputi Mekkah dan Madinah melintasi waktu 23 tahun dan mewarisi al-Qur'an dan hadis sebagai referensi/rujukan hidup sebagai muslim. Ketokohan itulah menjadikan Muhammad SAWsebagai figur dakwah (rijal ad-dakwah) dalam dakwah Islam dengan puncak kejayaan dakwahnya di Kota Madinah. Dari pengalaman tersebut, metodologi dakwah Nabi (manhaj) dakwah Muhammad SAW menjadi penting untuk diimplementasikan di wilayah Indonesia yang sarat dengan tantangan dakwah; pluralitas dan rawan konflik.

\section{PENGERTIAN METODOLOGI DAKWAH}

Metodologi berasal dari dua suku kata, method dan logos. Method berasal dari methodos yang berarti cara, teknik dan strategi. Logos adalah ilmu dan keilmuan. Jadi secara istilah, metodologi adalah cara atau teknik dan strategi untuk mendapatkan ilmu. ${ }^{4}$ Ilmu dalam bingkai ini dimaksudkan untuk menemukan dan mendapatkan ilmu yang ilmiah melingkupi kajian ontologis, epistemologis, dan aksiologis dari bidang kajian/ilmu yang dipelajari.

Dakwah berasal dari kata da'a, yad'u da'watan yang berarti mengajak, menyeru, dan mengundang. Secara istilah dakwah adalah aktivitas menyeru, mengajak, membimbing, mengundang orang lain (mad'u) kepada sistem Islam yakni terciptanya khoiru al-bariyyah, khoiru al-usroh, dan khoiru al-ummah. ${ }^{5}$

Metodologi dakwah adalah ilmu yang membahas pelaksanaan ajakan, seruan dan bimbingan kepada mad'u dengan memperhatikan ontologis, epistemologis dan aksiologis dari proses dakwah yang dilaksanakan. Objek kajiannya meliputi: da'i, metode, pesan, media, dan mad'u.

Da'i adalah orang yang menyeru, mengajak dan mengundang. Ada beberapa kompetensi da'i yang harus dimiliki; good will, good ethos, dan good moral character. ${ }^{6}$ Good will adalah sikap dan niat yang kuat dalam 


\section{Enung Asmaya: Implementasi Metodologi Dakwah Islam Nabi Muhammad SAW di Indonesia}

menjalankan misi dakwah. Good will sangat menentukan sikap da’i dalam melaksanakan aktivitas dakwah. Melalui will yang baik maka da'i akan merasa ringan dalam menghadapi tantangan dan memrpergunakan tantangan sebagai peluang yang akan dicapai secara maksimal. Good ethos adalah kemampuan dalam ilmu dan pengalaman. Melalui good ethos maka ia akan memiliki kecermatan dan kecepatan dalam menghadapi proses dakwah; ia cerdas, terampil, dan berwibawa. Good moral character adalah kepatuhan pada etika dan moral. Da’i mensyaratkan dirinya memiliki kebiasaan dan kehidupan yang baik, uswah hasanah dan figur yang mempesona baik fisik, psikis, sosial, maupun spiritual.

Metode dakwah artinya taktik, cara dan jalan. Dalam Bahasa Inggris disebut a way of doing anything...regularity and orderliness in action (jalan untuk melakukan sesuatu...aturan dan ketentuan dalam berbuat). ${ }^{7}$ Di dalam Bahasa Arab kata metode mengandung arti cara yang teratur dan berpikir baik-baik untuk maksud (dalam ilmu pengetahuan, dsb); cara kerja yang bersistem untuk memudahkan pelaksanaan sesuatu kegiatan guna mencapai tujuan yang ditentukan.

Dalam term dakwah, metode melalui tiga cara, hikmah, mauidzah hasanah dan mujadalah. ${ }^{8}$ Hikmah adalah sikap yang adil, memiliki sifat wara $̈$, mengetahui kebenaran dan beramal dengan kebenaran, memiliki pengetahuan tentang kebenaran, memiliki sikap bijaksana, memiliki kemampuan melaksanakan sunnah nabi dan memiliki sifat kenabian. ${ }^{9}$

Operasional dari metode bil hikmah, adalah seorang da'i akan mengedepankan pendekatan kejiwaan dalam melaksanakan dakwah, karena itu bil-hikmah, mengenal mad'u berdasarkan peta dirinya; ilmu pengetahuan, pengalaman dan kepribadian. Oleh karena itu, akan memperhatikan kapan bicara, kapan diam, kapan mendekat dan kapan menjauh, kapan memberikan maaf dan kapan memberi kabar mengancam.

Mauidzah hasanah adalah pendidikan, bimbingan, peringatan pelajaran yang baik atau nasehat dan pendidikan yang baik. Proses dakwah tidak mengenal pemaksaan kehendak kepada mad'u. ${ }^{10}$ Sebagai contoh $\mathrm{Mu}-$ hammad SAW juga tidak pernah memaksakan Sahabat Umar bin Khattab mengikuti ajarannya. Oleh karena itu, dengan bimbingan yang baik dan uswah hasanah Muhammad SAW mengantarkan Sahabat Umar bin Khattab masuk Islam. Padahal sebelumnya Sahabat Umar bin Khattab sangat benci kepada Muhammad SAW sekaligus menjadi "provokator" untuk membinasakan Muhammad SAW.

Melalui do'a dan harapannya, Muhammad SAW meminta kepada Allah SWT agar Sahabat Umar masuh Islam, dan akhirnya menjadi nyata. 
Sahabat Umar bin Khattab tercatat dalam sejarah sebagai khalifah yang memiliki keteguhan iman, kepekaan hati dan ide-ide cerdas dalam memikirkan dakwah Islam termasuk dalam membuka ijtihad-ijtihad baru yang sampai saat ini umat Islam menggunakannya; penetapan kalender hijriah, penetapan harta rampasan (fay), pembagian harta waris (ilmu faraid) dan hijab bagi perempuan. ${ }^{11}$

Pesan artinya sesuatu yang disampaikan. Pesan meliputi verbal dan non-verbal. Dalam dakwah pesan itu bersumber dari al-Qur'an dan hadis. ${ }^{12}$ Karena itu setiap pesan yang disampaikan akan merujuk al-Qur'an dan hadis, pendapat para sahabat dan kesepakatan ulama. Sebagai pesan dakwah, al-Qur'an dan hadis Nabi menjadi sesuatu yang tidak bisa dipisahkan, karena itu ada beberapa ayat al-Qur'an yang bersifat umum (mujmal) harus dirinci oleh hadis Muhammad SAW yang sahih yang bersifat terperinci. ${ }^{13}$

Demikian juga ada beberapa ayat al-Qur'an yang di-naskh oleh hadis yang dilihat ayat tersebut bersifat samar/tidak jelas, bersifat umum (mujmal), dan sejenisnya. Oleh karena itu, tujuan dari keduanya adalah: pertama, sebagai pembatalan hukum, kedua, pengecualian, ketiga, penjelasan dan keempat, penetapan hukum..$^{14}$ Namun demikian, hal ini tidak menyebabkan lemahnya al-Qur'an sebagai dasar hidup umat Islam. Oleh karena itu, wacana nasikh mansukh terjadi untuk menyempurnakan al-Qur'an dan meninggikan al-Qur'an.

Media dakwah adalah sarana yang digunakan dalam proses dakwah Islam. Media dakwah bisa melalui media tradisional dan modern. Media tradisional adalah media yang yang tidak berhubungan dengan teknologi, bersifat mekanis dan mengandalkan pada sarana alam. Beberapa contoh media tradisional adalah masjid, mushola, pengajian akbar, kentongan, beduk, rebana, dan sejenisnya. Sedangkan media modern adalah media yang syarat teknologis seperti koran, buku, radio, televisi. Media tradisional proses penyebarannya bersifat lambat dalam menjangkau mad'u, perlu waktu dalam proses penyebarluasan pesan, dan tidak menjangkau mad'u secara serentak. Hal itu berbeda dengan media modern, pesan dapat langsung disampaikan kepada mad'u secara serentak, serempak, menyeluruh, dan meluas. ${ }^{15}$

Mad'u adalah bagian dari proses dakwah Islam. Mad'u adalah sasaran dakwah yang penting untuk diperhatikan keberadaannya; usia, jenis kelamin, pengetahuan, kebiasaan, minat, pendidikan dan pengalaman keagamaan. Mengenal mad'u dengan cermat akan mengantarkan proses dakwah yang baik pula. Oleh karena akan menerapkan metode/pendekatan, pesan dan media dakwah yang relevan dengan mad'u. Hal itu bertujuan 
agar dakwah berjalan efektif; dapat dimengerti, melahirkan rasa senang, melahirkan sikap positif, dan dapat ditindaklanjuti/dilaksanakan mad'u. ${ }^{16}$

Secara epistemologis, dakwah Islam adalah mekanisme pelaku dakwah dalam pencapian tujuan dakwah adalah dengan melewati beberapa tahapan dakwah. Tahapan dakwah adalah langkah-langkah yang harus dilewati pelaku dakwah. Sebagai da'i tahapan yang harus dilewati adalah dengan mempersiapkan bekal fisik, psikis, sosial, dan spiritual. Maksudnya adalah aktivitas dakwah memerlukan persiapan lahir dan batin bagi pelaku dakwah agar misi bisa dilaksanakan dan dicapai dengan baik. Bekal fisik adalah bekal kesehatan. Bekal psikis, semangat dan sikap dan baik. Bekal sosial adalah bahagia, ceria, dan positif thinking. Bekal spiritual adalah bekal ilmu agama, ikhlas, uswah hasanah, kepatuhan dan ketaatan pada ajaran agama, serta memiliki akhlak yang mulia.

Secara aksiologis, dakwah Islam bermanfaat dalam perubahan individu, keluarga dan masyarakat agar menjadi lebih baik. Perubahan masyarakat menuju masyarakat yang berkeadaban dapat diperjuangkan melalui gerakan dakwah Islam (harakah Islamiyah). Hal ini pernah dilakukan Muhammad SAW dalam mengubah masyarakat Madinah yang rawan konflik dengan prinsip dakwah yang dipegangnya mengantarkan Madinah menjadi kota yang beradab bagi masyarakat muslim dan nonmuslim. ${ }^{17}$ Masyarakat merasakan kedamaian dan keharmonisan dalam hidup berdampingan; ada kemerdekaan untuk menjalankan agama sesuai dengan keyakinan dan tidak saling menghina.

Demikian juga dakwah Islam telah dilakukan oleh pejuang Islam Indonesia tempo dulu yang membawa kemerdekaan Republik Indonesia dari tangan penjajah/imperialisme Barat. ${ }^{18}$ Melalui kalimat Allahu Akbar maka spirit kemajuan dapat tertanam kuat dalam relung jiwa masyarakat Indonesia, untuk memerintahkan kebaikan (ma'ruf) dan mencegah perbuatan yang buruk (munkar) atau dalam istilah lain disebut amar ma'ruf nahyi munkar. ${ }^{19}$

\section{FIGUR NABI MUHAMMAD SAW}

Nabi Muhammad SAW lahir 12 Rabiul Awal/ 20 April 570 M/13 Rabiul Awal 632 H. Ia keturunan dari Suku Quraisy yang berada di kota Mekkah. Ayahnya bernama Abdullah, ibunya bernama Aminah dan kakeknya bernama Abdul Muthalib ${ }^{20}$ dan uyutnya bernama Hasyim ${ }^{21}$ (disebut selanjutnya Bani Hasyim). ${ }^{22}$ Sebagai keluarga besar Nabi SAW melewati masa kecil dengan prihatin, karena di antara keluarga besarnya keluarga abdul Muthalib tergolong tidak kaya, pendapatan keluarga mengandalkan peker- 
jaannya pada jabatan syiqayah yakni pengawas mata air zam-zam untuk dipergunakan oleh para penziarah. Jabatan ini kurang menguntungkan dibandingkan jabatan lainnya seperti liwa (jabatan ketentaraan), diyat (kekuasaan hakim sipil dan kriminal), sifaarah (kuasa usaha negara), khizanah (jabatan administrasi keuangan), dan nadwa (ketua dewan). Dengan demikian, Muhammad SAW berasal dari keluarga terhormat yang relatif miskin.

Muhammad SAW terlahir yatim karena ayahnya meninggal dunia saat ia berada dalam kandungan. Kendati yatim namun kasih sayang tidak bertepi diterima oleh Muhammad SAW kecil, karena banyak keberkahan yang didapat oleh setiap orang yang mengasuhnya. ${ }^{23}$ Oleh karena pertimbangan ekonomi, akhirnya Muhammad SAW dkembalikan kepada ibunya. Sang ibu merasa gembira karena Muhammad SAW memiliki badan yang sehat, budi bahasanya halus, pikirannya cerdas, jiwanya murni, dan raut wajahnya yang simpatik hingga menarik setiap orang yang melihatnya.

Muhammad SAW menjadi pribadi yang tertata baik, hal ini sesuai dengan do'a dan harapan kakeknya agar Muhammad SAW menjadi orang yang terpuji. ${ }^{24}$ Sifat terpuji Muhammad SAW, mengantarkannya pada sebuah gelar/sebutan al-Amin yang artinya dapat dipercaya.$^{25}$ Dalam berkeluarga, Muhammad SAW menjadi suami yang baik untuk istrinya Khadijah ${ }^{26}$ dan kelima anak-anaknya (al-Qasim, Abdullah, Zainab, Ruqoyyah, Ummu Kalsum dan Fatimah). Mereka hidup bahagia dan saling mencintai.

Sifat terpuji Muhammad SAW merupakan bentuk Allah SWT kepada sang calon rasul yang maksum dari segala kemaksiatan dan kesalahan. Di samping itu sebagai calon rasul, telah dianugerahi beberapa ciri istimewa (berbeda pada umumnya masyarakat), tanda-tanda kenabian Muhammad SAW, adalah:

"Anak-anak Halimah seringkali mendengar suara yang memberikan salam kepada Muhammad SAW: assalamu'alika ya Muhammad, padahal mereka tidak melihat ada orang yang memberikan salam itu. Pada hari yang lain Dimrah anak Halimah, berlari-lari pulang sambil menangis. Dengan terbata-bata ia berkata bawa ada orang yang menangkap Muhammad SAW. Orang itu besar-besar dan berpakaian putih. Halimah bergegas menyusul Muhammad SAW, ia mendapatkannya sendirian tengah menengadah ke langit. Setelah ditanya oleh Halimah, Muhammad SAW menjawab "Ada dua malaikat turun dari langit. Mereka memberikan salam kepadaku, membaringkanku, membuka bajuku, dan membelah dadaku, membasuhnya dengan air yang mereka bawa lalu mereka menutup dadaku kembali tanpa aku merasa sakit, tidak ada luka dan tidak ada bekasnya. Kedua malaikat itu baru saja menghilang ke angkasa." Halimah tentu merasa gembira melihat anak asuhnya selamat tanpa cedera apapun. ${ }^{27}$

Dalam riwayat lain, disampaikan: "bahwa Muhammad SAWsejak bayi telah memperlihatkan keistimewaan yang tidak terdapat pada bayi-bayi 
lain, pertumbuhan badannya sangat cepat. Pada usia lima bulan Muhammad SAW sudah pandai berjalan dan pada usia sembilan bulan ia sudah bisa berbicara. Pada usia dua tahun ia sudah bisa dilepas bersama-sama anak Halimah untuk menggembala kambing." ${ }^{28}$

Dalam pengalaman lain, saat Muhammad SAW dalam melaksanakan perjalanan, "Bahwa iringan kafilah Abi Thalib bergerak ke utara menuju Suriah. Sinar matahari yang panas terik membakar rombongan musafir tidak dirasakan oleh Muhammad SAW, karena segumpal awan menggantung di atas kepalanya bagaikan sebuah payung yang selalu menaunginya. Awan itu bergerak mengikuti gerak kafilah da’i pagi hingga sore. Jika kafilah berhenti maka awan itu turut berhenti." 29

Tanda-tanda kenabian tersebut menjadi sebuah kenyataan, bahwa Muhammad SAW adalah seorang rasul, tepat pada usia empat puluh tahun. ${ }^{30}$ Kehadiran seorang nabi atau rasul menurut Abu Bakar al-Jazairy adalah karena beberapa hal; pertama, al-Mistaliyah (keteladanan), artinya seorang manusia diangkat menjadi nabi haruslah memiliki kemanusiaan yang sempurna baik fisik, akal pikiran maupun rohani. ${ }^{31}$

Kemanusiaan yang sempurna baik fisik, akal pikiran maupun rohani. Sikap, ucap, dan perbuatan menjadi uswah hasanah dan membuat manusia kagum padanya. Kedua, syaraf an-Nasab (keturunan yang mulia), artinya seseorang yang diangkat menjadi nabi haruslah dari keturunan yang mulia. ${ }^{32}$ Mulia adalam pengertian umum yakni terjauh dari segala bentuk kerendahan budi dan perilaku yang menyebabkan jatuhnya derajat dan nilai-nilai kemanusiaannya. Ketiga, 'amil az-Zaman (dibutuhkan zaman), artinya kehadiran seorang nabi karena dibutuhkan masyarakat untuk mengisi kekosongan ruhani, memperbaiki kerusakan masyarakat dan mengembalikan manusia kepada kehidupan yang sesuai dengan fitrah penciptaannya. ${ }^{33}$ Muhammad SAW adalah pembawa risalah pembawa pedoman dalam perbaikan manusia dan rujukan dalam hidup dan kehidupan umat manusia.

\section{DAKWAH MUHAMMAD SAW}

Muhammad SAW lahir di Mekkah yang menganut keyakinan pada patung dan berhala (disebut selanjutnya paganisme). Keyakinan tersebut merupakan keyakinan yang turun-temurun diwariskan dari nenek moyang, termasuk kebudayaan jahilnya (disebut selanjutnya zaman jahiliyah). ${ }^{34}$ Keyakinan dan tradisi yang sudah lama dan kuat mengakar pada masyarakat Mekkah, mengakibatkan dakwah Muhammad SAW senantiasa mendapat tantangan serta rintangan dari kaum kafir dan ahli kitab. ${ }^{35}$ Tidak sedikit 
hinaan, ejekan, perlakuan buruk bahkan pengusiran, pemboikotan, dan pembunuhan terhadap Muhammad SAW dan sahabat-sahabat kecilnya acapkali terjadi.

Faktor-faktor yang menyebabkan kaum kafir dan ahli kitab enggan menerima ajaran Muhammad SAW adalah: pertama kepentingan agama, artinya agama menjadi bagian sensitif bagi setiap umat manusia. Agama tidak bisa digantikan oleh agama baru kecuali adanya kesadaran bahwa agama lamanya sudah tidak memberikan kepuasaan ruhani. Penolakan akan dilakukan terhadap apapun dan kepada siapapun yang berusaha menggantikan agama yang dianutnya. Oleh karena itu, agama bagi setiap individu penting dan menjadi penuntun dalam hidup dan kehidupan. Bagi kaum kafir Mekkah kedatangan ajaran baru yang dibawa Muhammad SAW adalah mengancam keberadaan agama yang dianutnya. Ajaran Muhammad SAW adalah akan menggantikan keyakinan mereka sebelumnya yang sudah mengakar kuat dalam pikiran mereka.

Kedua, kepentingan politik, artinya manusia tidak lepas dari kehidupan berpolitiknya. Politik adalah cara seseorang untuk menguatkan keberadaan dirinya di tengah-tengah masyarakat. Melalui politik, seseorang akan bisa menjadi penguasa, mengatur dan mengarahkan orang lain. Banyak cara masuk dalam kegiatan politik, salah satunya menjadi orang yang berpengaruh di hadapan masyarakat; baik melalui ekonomi, sosial, budaya, bahkan "nabi”. Bagi masyarakat Mekkah, profesi baru Muhammad SAW mengajak banyak orang masuk ke dalam agama Islam, secara otomatis mengancam kekuasaan mereka sebelumnya yang telah mendapat kekuatan massa dan pengaruh. Oleh karena itu, keberadaan Muhammad SAW sangat mengancam posisi strategis mereka.

Ketiga, kepentingan ekonomi, artinya ekonomi menjadi alasan persaingan dan permusuhan antara satu dengan lainnya. Kepentingan ekonomi berkaitan dengan hajat hidup manusia akan pemenuhan sandang, pangan dan papan. Adapun cara-cara untuk memenuhi hajat tersebut adalah dengan menjaga pekerjaan lama mereka sebelum mendapat lahan pekerjaan lain yang lebih menjanjikan. Mereka tidak akan menerima dan sepakat manakala lahan pekerjaannya sebagai tumpuan hidupnya diganggu oleh siapapun.

Bagi masyarakat paganis, pekerjaan membuat patung adalah profesi yang menjanjikan karena akan banyak pesanan pembuatan patung untuk setiap orang yang menyembahnya. Sebaliknya, jika paganisme itu dianggap tidak lagi relevan dan harus diganti dengan sembahan baru yakni dzat yang gaib Allah SWT maka akan mengancam pendapatan mereka. Ketiga 
faktor tersebut menjadi alasan pemboikotan dan penyiksaan orang-orang kafir Mekkah kepada Muhammad SAW atas perjuangannya dalam dakwah Islam saat itu.

Dakwah Muhammad SAW periode Mekkah mengantarkan pada peta dakwah sebagai berikut: pertama, pendekatan dakwah dilakukan secara sembunyi-sembunyi (dakwah bi sirr). Dakwah di Mekkah dengan menguatkan keluarga dan sahabat-sahabat terdekatnya yang disebut assabiquna al-awwalun adalah: Khadijah (istri), Abu Bakar (sahabat karibnya sejak masa kanak-kanak), Ali bin Abi Thalib (saudara sepupunya yang baru berumur 10 tahun), Ummu Aiman (pengasuh Muhammad SAW sejak ibunya masih hidup) dan Zaid bin Harisah (bekas budaknya yang menjadi anak angkatnya). ${ }^{36}$

Beberapa sahabat ini menerima dakwah Muhammad SAW lalu mereka kembangkan kepada sahabatnya yang lain, maka muncul mualaf-mualaf Islam yang jumlahnya semakin banyak. Abu Bakar sendiri kemudian berhasil mengislamkan beberapa teman dekatnya, seperti: Usman bin Affan, Tholhah bin Ubaidilah, Zubair bin Awam, Saad bin Abi Waqas, Abdurahman bin Auf, dan Zubair bin Awwam. Dakwah bi-sirr, sangat efektif dalam merengkuh hati orang-orang yang dekat di hatinya (keluarga dan sahabatsahabatnya).

Kedua, pesan fokus pada perbaikan akidah/keyakinan. ${ }^{37}$ Pesan yang memberitahukan tentang Tuhan yang harus disembah (Allah SWT) dan Muhmmad SAW yang sesuai dengan ajaran yang dibawa oleh Nabi Ibrahim AS, Nabi Nuh AS, Nabi Musa AS dan Nabi Isa AS). Hal ini dilakukan karena mengesakan Allah SWT (tauhidullah) merupakan misi utama para nabi. Akidah menjadi penuntun dalam pikir, lisan, dan perbuatan seseorang.

Dalam Islam, aqidah diartikan sebagai ittiqadun bil jannani, wa nuthqun bi lisani, wa 'amalin bil arkaani. Oleh karena itu, aqidah menjadi pondasi dalam melaksanakan hidup dan kehidupan, dalam bidang ekonomi, politik, sosial, dan budaya. Aqidah menjadi orientasi dan penuntun hidup manusia, karena mulai di Mekkah Muhammad SAW mengembangkan misi tauhidullah.

Ketiga, media dakwah yang digunakan Muhammad SAW saat berdakwah di Mekah, adalah media tradisional berupa bait al-arkam (rumah kediaman Arkam). Media ini menjadi sarana dakwah Muhammad saat masyarakat kafir mencari tahu kegiatan dakwah yang dilakukannya. Keempat, metode dakwah yang digunakan adalah bil hikmah dan mauidzah hasanah. Metode ini dilakukan karena yang menjadi sasaran dakwahnya orang-orang terdekatnya yang sudah diketahui pengetahuan dan pengala- 
man agamanya. Memberikan nasihat yang baik dan uswah hasanah menjadi metode yag efektif dalam dakwah Muhammmad SAW. Ketertarikan keluarga dan sahabat karena Muhammad SAW telah memiliki pribadi yang dapat dipercaya dan tidak pernah berbohong (kredibilitas positif).

Dakwah Mekkah berbeda dengan dakwah saat Muhammad SAW berada di kota Madinah. Kota Madinah menjadi alasan Muhammad SAW untuk melanjutkan dakwahnya, karena di kota tersebut telah ada sebagian muslim yang bertempat tinggal (kaum Anshar) dan ada seorang raja Madinah bernama Raja Negus yang bersedia menerima kedatangan Muhammad SAW dan rombongan (kaum Muhajirin) untuk tinggal dan bersama di Madinah. Proses dakwah di Madinah relatif tidak terlalu lama (10 tahun dibanding dengan masa pelaksanaan dakwah di Mekkah 13 tahun).

Strategi dakwah Muhammad SAW saat di Madinah, adalah: Pertama, Muhammad menjadikan negara Madinah sebagai pusat dakwah Islam. Artinya, Muhammad sebagai pemimpin agama sekaligus pemimpin negara, selain sebagai rasul ia juga pelayan administrasi rakyat. Muhammad SAW tidak hanya pandai dalam meyakinkan akidah Islam namun juga pandai memberi layanan dan konsultasi pemerintahan. Semasa Muhammad SAW memimpin, banyak kepentingan ekonomi, politik, dan budaya yang harus disebarkan kepada seluruh penduduknya. Kedua, melakukan pembinaan hubungan sesama muslim (ukhuwah islamiyah). Persaudaran sesama muslim benar-benar diperhatikan guna menjaga dakwah Islam di Madinah terus berjalan. Hal itu dapat dimaklumi karena selama berada di Kota Madinah, kaum Anshar dan kaum Muhajirin acapkali berbeda pendapat dan kepentingan.

Ketiga, mempersaudarakan muslim dan non-muslim (ukhuwah insaniah). Persaudaraan ini dimaksudkan agar hubungan muslim dan nonmuslim tetap terjalin baik, tidak ada perang dan tindakan yang mengganggu stabilitas Madinah. Mereka diberikan kebebasan dan perlindungan untuk menjalankan agama sesuai dengan keyakinan masing-masing. Keempat, membangun Masjid Nabawi. Pembangunan masjid itu sebagai simbol tempat pertemuan bagi Muhammad SAW dan penduduk Madinah dalam menyelesaikan dan merencanakan dakwah Islam ke depan. Oleh karena itu, dakwah Muhammad SAW antara Mekkah dan Madinah menjadi insipirasi dakwah bagi rijal dakwah di dunia Islam.

\section{PROBLEMATIKA DAKWAH ISLAM DI INDONESIA}

Kemunduran Islam periode pertengahan (Kerajaan Islam Turki Usmani, Kerajaan Islam Syafawi Persia dan Kerajaan Islam Moghul India) 
mengantarkan Barat/Negara Eropa (Inggris, Perancis, Italia, Belanda, dan Portugis) pada kebangkitan dan kekuatannya. Beberapa negara Asia termasuk Indonesia menjadi negara jajahan yang dikuasai dan ditundukkannya. Barat melakukan penjajahan dengan tiga tujuan, ${ }^{38}$ (1) gold, yakni kepentingan kekayaan dan kebutuhan harta dan emas (gold) yang subur, makmur dan kaya raya; (2) glory, yakni kepentingan pada kekuasaan dan dapat berkuasa terhadap seluruh aspek yang dmiliki tanah jajahan; dan (3) gospel, yakni pada kepentingan syiar agama Kristen agar menjadi agama mayoritas di tanah jajahan.

Selama 3 abad lebih, penjajah melakukan tindakan ekspansi (perluasan wilayah) di Indonesia mulai dari Maluku, Timor-Timur, Ambon (Indonesia bagian timur) juga sampai ke Jawa (Indonesia bagian tengah) dan Sumatra (Indonesia bagian barat). Wilayah jajahan menjadi objek dari tiga misi penjajahan (gold, glory, dan gospel). Dalam bidang gold, penjajah memanfaatkan kesuburan tanah Indonesia dalam menumpuk hasil panen; makanan pokok; beras, gandum, sagu, singkong, umbi-umbi, buah-buahan, ikan, sayur, dan sejenisnya. Tidak hanya dinikmati saat mereka berada di Indonesia tetapi juga dibawa ke negera asalnya untuk ditanam dan dikembang-biakkan di negara asalnya. Maka tidak heran pada beberapa negara Barat juga dikenal bahan makan pokok, buah-buahan, dan lain-lain yang jenisnya sama dengan yang ada di Indonesia. Akibatnya, rakyat Indonesia miskin, kelaparan, dan kesulitan dalam mendapatkan hasil panen.

Dalam bidang glory, penjajah telah menaklukan rakyat Indonesia untuk tunduk patuh pada perintahnya. Melalui politik devide et empira (politik adu domba), rakyat tidak lagi bersatu. Bangsawan dan tokoh masyarakat diberi kekayaan dan kekuasaan sebagai pejabat wilayah yang bertujuan untuk "menutup" akses dan keberanian rakyat dalam melakukan pemberontakan kepada penjajah. Rakyat sulit bersatu bahkan saling mencurigai dan saling tidak percaya yang akibatnya sulit melawan penjajah, terlebih penjajah telah memiliki pertahanan militer yang kuat dan siap menghadapi perlawanan dari rakyat Indonesia.

Dalam bidang gospel, penjajah berusaha untuk melakukan penyebarluasan Agama Kristen di tanah jajahan. Hal ini dilakukan karena penjajah memiliki dendam masa lalu kepada umat Islam masa klasik yang berhasil mengambil tanah Eropa (Spanyol dan Konstantinopel). Balas dendam yang mengantarkan penjajah pada upaya "pengusiran" muslim, dalam kuantitas dan kualitas. Muslim dianggap sebagai kelompok kelas dua (the second class) setelah Kristiani, kegiatannya hanya cukup di masjid, membaca alQur'an, wirid, dan dzikir serta tidak harus berpolitik. Muslim dikondisi- 
kan sebagai individu yang bodoh, miskin, dan terbelakang. Penjajah tidak segan-segan untuk menghancurkan karakter muslim sekaligus menutup kesempatan akses politik, ekonomi, dan pendidikan.

Dari beberapa hal di atas dapat disimpulkan bahwa kondisi kebangkitan muslim Indonesia pasca kemerdekaan belum dapat dilakukan secara maksimal. Namun setelah berdirinya beberapa organisasi keagamaan seperti Muhammadiyah, al-Irsyad, NU, Persis, umat Islam Indonesia memperlihatkan kemajuan dan kebangkitannya untuk menunjukkan kekuatannya. ${ }^{39}$ Kendati demikian, tetap tidak dapat dipungkiri ada beberapa karakter muslim Indonesia hasil "pendidikan" para penjajah masih menyisakan beberapa sifat sebagai berikut: bersikap toleran dengan perbedaan, memiliki sikap positif kepada "orang asing", mudah berpecahbelah dan kurang percaya diri. Oleh karena itu, ciri-ciri tersebut menjadi problem dalam misi perubahan masyarakat muslim Indonesia (dakwah Islam Indonesia).

Pertama, bersikap toleran dengan perbedaan, baik agama, suku, bahasa, bahkan bangsa. Semua itu dianggap sunatullah (garis Allah SWT) yang harus diterima dan dimaafkan. Hal ini terbentuk karena awal mula Islam, masyarakat mengenal dengan alam yang toleran dan menjunjung kearifan lokal. Namun, karakter ini menjadi "tidak peka" dengan ancaman yang akan menyerang dan "menjajah" umat Islam sendiri. Melalui bujukan harta, materi, jabatan, dan kekuasaan mengakibatkan mata dan hati umat Islam buta dalam kebenaran (toleransi dengan menghilangkan shibghah).

Kedua, sikap positif kepada "orang asing", maksudnya sikap terbuka umat Islam terhadap “orang asing” (disebut Barat/non-muslim) untuk ikut serta dalam pengaturan pertumbuhan dan perkembangan umat Islam, akan menyebabkan segala rahasia "negara kecil Islam" diketahui. Kelemahan dan kekuatan umat Islam akan dikenali dan akan dibaca sebagai sasaran tembak mereka dalam menaklukkan dan "menghancurkan" umat Islam, baik secara langsung ataupun diam-diam. Keterlibatan orang asing di tengah-tengah "negara kecil Islam" menjadi tantangan dalam penyebarluasan dakwah Islam di Indonesia, karena itu mereka akan melakukan penjajahan secara non-fisik berupa penyebarluasan budaya Barat: pornografi, pornoaksi, sifat individualisme, materialisme, dan kapitalisme.

Ketiga, mudah berpecah-belah. Umat Islam dengan ideologi dan akar sejarah berdirinya yang berbeda-beda, mengakibatkan satu organisasi Islam dengan orgnisasi lainnya saling mencurigai, saling mengkafirkan dan saling menghujat. Kondisi ini mengakibatkan persatuan dan kesatuan umat Islam terpecah dan tidak menggalang satu kekuatan dalam kemajuan umat 
Islam. Gerakan dakwah tersekat dengan kelompok dan golongan, tidak ada kepedulian dengan kelompok lain, yang penting kelompoknya sehat, aman, sejahtera. Oleh karena itu, mudahnya berpecah-belah antara umat Islam di Indonesia mengakibatkan dakwah Islam mengalami problem tersendiri.

Keempat, kurang percaya diri (lost confident). Muslim sejak awal penjajahan senantiasa didoktrin dengan kelompok kelas dua, yang bodoh dan terbelakang. Stereotip tersebut didasarkan pada kepentingan penjajah agar umat Islam mundur dan tidak percaya diri dalam memangku kemajuan. Dengan demikian, timbul persepsi bahwa menjadi seorang muslim itu memalukan dan merusak pencitraan diri. Terlebih dengan dimunculkannya secara besar-besaran oleh media Barat bahwa muslim itu teroris dan haus darah. Kondisi tersebut mengantarkan kondisi psikis muslim menjadi lemah dan terpuruk tidak semangat, akibatnya banyak muslim yang malu (lost confident). Padahal hal tersebut semata-mata politik Barat dalam menghancurkan karakter umat Islam. Dalam kenyataannya, menjadi seorang muslim di Indonesia harus berhadapan dengan arus global yang rata-rata bersumber dari Barat; food, fun, fashion, dan film.

\section{IMPLEMENTASI METODOLOGI DAKWAH MUHAM- MAD SAW DALAM KONTEKS KE-INDONESIA-AN}

Muhammad SAW adalah teladan dalam melakukan dakwah Islam. Namun, dalam melaksanakan dakwah Islam, terdapat perbedaan dan persamaan. Perbedaannya masa Muhammas SAW, wilayah dakwahnya adalah masyarakat yang menganut paganisme (menyembah patung dan berhala). Sedangkan muslim Indonesia berada dalam kondisi pasca animisme dan dinamisme serta serbuan tangan-tangan penjajah. Beberapa problem dakwah Islam di Indonesia antara lain kurang percaya diri (lost confident), mudah berpecah-belah, sikap positif kepada "orang asing", bersikap toleran dengan perbedaan. Oleh karena itu, dengan pendekatan mengambil pola dakwah Muhammad SAW, diupayakan dapat menemukan prinsip dakwah yang solutif adalah sebagai berikut.

1. Fokus kepada da’i

Da'i dalam proses perubahan masyarakat sangat penting untuk diperhatikan. Kegigihan da'i dalam ilmu dan amal usaha dalam membawa visi dan misi dakwah Islam menjadi syarat dalam proses dakwah Islam. Melalui syarat tersebut akan lahir da'i-da’i yang mampu mengikat lahir dan batin mad'u dalam mengikuti pesan dakwah yang diajarkan. Sebagaimana Muhammad SAW, ia dengan gigih menjadi uswah hasanah dalam ilmu dan amal perbuatan. Melalui bimbingan Allah SWT, Muhammad memiliki 
ilmu yang hebat, “mukjizat” berupa al-Qur'an sebagai pesan sucinya sekaligus beberapa nubuah yang membuktikan kehebatan Muhammad SAW sebagai utusan Tuhan. Bagi manusia yang bukan nabi dan rasul, tentunya ilmu pengetahuan agama dan pengamalan agama yang mapan agar mampu meyakinkan mad'u bahwa ia benar-benar sebagai da'i yang mengajak pada kebaikan dan mencegah kepada kemunkaran.

Melalui fokus pada da'i tersebut, kesulitan dakwah berupa lost confident yang dirasakan umat Islam tidak lagi muncul. Oleh karena umat Islam sebagai mad'u dalam hal ini memiliki da’i yang membanggakan tidak hanya intern muslim tapi juga non-muslim/Barat nasional bahkan internasional. Keteguhan pada prinsip dakwah Islam dan komitmen yang kuat dalam memajukan umat Islam serta syiar Islam maka umat Islam akan terangkat derajat dan citranya di mata dunia.

Kepercayaan diri yang terbangun baik, akan mengantarkan pada keingintahuan seseorang untuk melakukan sesuatu. Oleh karena itu, tugas da'i tidak hanya mapan dalam ilmu agama tetapi juga mampu membaca situasi dan kondisi, cerdas dan cermat dalam menangkap peluang kemajuan untuk umat Islam dengan tetap memegang teguh aqidah Islam yang menyinari dalam amal usaha.

\section{Fokus kepada pesan dakwah}

Pesan dakwah adalah bagian yang harus disampaikan oleh da'i, baik verbal maupun non-verbal, lisan atau tulisan. Pesan yang baik adalah pesan yang mampu mengikat hati muslim dengan Tuhannya, mengikat hati dengan teman seagamanya, memberi dorongan untuk mengais dunia dengan sungguh-sungguh serta menjadi pendorong pada perubahan dunia akhirat menjadi lebih baik. Pesan utama dan pertama adalah mengajak agar muslim beraqidah Islam, beriman kepada Allah SWT dan komitmen dengan sunnah-sunnah yang diajarkan oleh Muhammad SAW. Pesan kedua adalah ajaran tentang hidup dan kehidupan dengan tauhid Allah sebagai poros dari semua amal usaha. Hal in telah dicontohkan Muhammad SAW selama periode Mekah dan Madinah, yang mengantarkan pada kekuatan umat Islam pada fase penerusnya (khulafa ar-Rasyidun). Kelemahan umat Islam yang mudah berpecah-belah akan terkikis dengan menyatukan hati dan mengikatkan persamaan melalui akidah Islam, sebagaimana kekuatan Muhammad SAW bersama para sahabatnya dalam menjalankan misi Islam.

\section{Fokus kepada media dakwah}

Sebagai seorang yang membawa misi perubahan maka ada banyak ikhtiar yang harus dilakukan oleh seorang da'i. Muhammad SAW mencoba dakwah dengan berbagai media, mulai dari rumah sebagai media dak- 

di Indonesia

wahnya, dilanjutkan ke masjid dan mushola (tempat sujud), selanjutnya ke media yang lebih dapat dijangkau banyak mad'u adalah lapangan dan pendirian sebuah negara Madinah. Artinya, untuk mengangkat popularitas muslim di mata dunia, maka umat Islam harus melakukan syiar/show up diri sebagai muslim tidak hanya dalam ranah kecil rumah dan masjid melainkan ranah publik, sehingga dunia bisa menyaksikan kemajuan umat Islam. Manakala hal itu sudah dapat dilakukan maka Barat akan segan dan takut kepada umat Islam serta tidak akan serta merta menjajah umat Islam. Oleh karena itu, menjadi sebuah keniscayaan muslim Indonesia berpikir global dalam mengawal umat Islam.

\section{Fokus kepada metode}

Metode seringkali disebut sebagai tharikah yang lebih penting dari maddah (metode lebih penting dari pesan). Artinya, metode dan cara akan menentukan efektivitas pesan itu diterima. Oleh karena dengan pendekatan metode maka da'i akan menetapkan metode sesuai dengan sasaran dakwah yang dihadapi. Ia akan menerapkan metode sembunyi-sembunyi dengan pesan-pesan yang persuasif manakala situasinya tidak mendukung, dan sebaliknya akan lantang, tegas, jelas, dan terang-terangan ketika situasinya mendukung. Oleh karena itu, metode dakwah juga bisa dilakukan dengan kekuasaan (yaddun), nasihat (lisan), dan dukungan (do’a) sesuai dengan situasi mad'u. Oleh karena itu, tujuan dari metode itu dipikirkan agar mad'u mengerti, senang, memiliki sikap positif, dan dapat menjalankan pesan yang disampaikan. Muhammad SAW adalah seorang da'i yang cermat dalam menentukan metode dakwah sehingga semakin waktu berjalan pengikut atas sunah-sunahnya semakin banyak.

\section{Fokus kepada mad'u}

Muhammad SAW memberikan perhatian kepada mad'u sebagai kelompok yang tidak dapat dipisahkan darinya. Ia banyak memberikan perhatian atas pemenuhan hak dan kewajiban mad'u sebagai warga negaranya saat ia berada di Madinah, membuat aturan dan perundangan yang mengatur kehidupan bersama agar hidup rukun dan damai. Aturan dan perundangan yang telah disepakati bersama menjadi payung dalam melaksanakan aktivitas agar semuanya yang membuat aturan bisa melaksanakannya. Oleh karena itu, aturan menjadi supremasi hukum dalam kepemimpinan Muhammad SAW.

Mad'u yang beragam tidak menjadi problem berarti bagi Muhammad SAW karena ia berlaku adil kepada siapapun; kaum Anshar, Muhajirin, Muslim, non-muslim semuanya diperhatikan sama. Ada beberapa fokus Muhammad SAW kepada mad'u saat itu; persamaan hak (faham egali- 
terianisme, keadilan, kesejahteraan, demokrasi, dan supremasi hukum). Diharapkan semua mad'u dapat memahami hidup bersanding dalam perbedaan tetapi damai dan aman.

\section{KESIMPULAN}

Metodologi Dakwah Muhammad SAW menjadi inspirasi bagi rijal aldakwah, baik kepada da'i, metode, pesan, media dan mad'u. Hal ini karena ia adalah figur dakwah yang telah membawa Islam dalam perkembangannya mulai dari periode Mekkah hingga Madinah yang sarat dengan situasi sosial berbeda yang mengantarkan pada metodologi yang khas dan berbeda pula namun dirangkai menjadi satu kesatuan yang tidak bisa dipisahkan dari sosok Muhammad SAW dalam melaksanakan dakwah Islam.

Problematika dakwah Islam di Indonesia adalah harus berhadapan dengan maraknya kurang percaya diri, mudah berpecah-belah, sikap positif kepada "orang asing", dan bersikap toleran dengan perbedaan. Untuk mengatasi hal tersebut maka diperlukan da'i yang gigih dalam ilmu dan amal usaha dalam membawa visi dan misi dakwah Islam. Ia juga gigih menjadi uswah hasanah dalam ilmu dan amal perbuatan, teguh pada prinsip dakwah Islam, dan komitmen yang kuat dalam memajukan umat serta syiar Islam.

Pesan dakwah berorientasi pada al-Qur'an, disempurnakan oleh hadis, ditambah dengan pendapat sahabat dan ulama. Media dakwah dari rumah sebagai media dakwahnya, dilanjutkan ke masjid dan mushola (tempat sujud), selanjutnya ke media yang lebih dapat dijangkau banyak mad'u yakni berdakwah secara struktural. Metode yang digunakan dengan sembunyisembunyi dan terang-terangan. Oleh karena itu, metode dakwah juga bisa dilakukan dengan kekuasaan (yaddun), nasihat (lisan), dan dukungan (do’a) sesuai dengan situasi mad'u. Tujuan dari metode itu agar dakwah berjalan efektif. Bidang garapan mad'u, senantiasa memberikan perhatian atas pemenuhan hak dan kewajiban mad'u sebagai warga negara, dari oleh dan untuk masyarakat muslim Indonesia. Aturan dan perundangan yang telah disepakati bersama menjadi payung dalam melaksanakan aktivitas. Hal ini karena supremasi hukum menjadi ciri kepemimpinan Muhammad SAW dalam berdakwah.

\section{ENDNOTES}

${ }^{1}$ Keragaman suku, agama, bahasa, bangsa serta hidup berfoya-foya menjadi salah satu alasan kehancuran kerajaan Islam klasik, termasuk Dinasti Abasiyah di 


\section{Enung Asmaya: Implementasi Metodologi Dakwah Islam Nabi Muhammad SAW di Indonesia}

Baghdad, Kerajaan Islam di Spanyol, dan Kerajaan Usmani di Turki. Ketiga dinasti ini memiliki wilayah yang tersebar luas, meliputi Arab, Persia, Turki, bahkan sebagian Eropa. Namun kelemahan dari ketiga kerajaan tersebut tidak mampu memberi kesejahteraan secara merata, kurang komunikasi dan koordinasi, para raja berfoya-foya serta lemahnya administrasi. Heterogenitas penduduk membutuhkan perhatian, kemajuan militer, serta peradaban. Turki merupakan kerajaan Islam yang populer dengan kekuatan jenisari atau inkisyariahnya/kader-kader militer yang tangguh dan hebat, namun ketika peradaban menjadi bagian yang tidak "dijaga" tumbuh kembangnya maka masyarakat menjadi lemah dan mudah ditundukkan lawan/musuh yang akhirnya tidak lagi memiliki pertahanan untuk menjaga keutuhan kerajaan.

${ }^{2}$ Sejarah Islam mencatat peristiwa jatuhnya Dinasti Abasiyah akibat propinsipropinsi kecil yang banyak dan tersebar akhirnya melakukan pembangkangan dan terlepas dari kekuasaan Dinasti Abas akibat lemahnya kordinasi dan konsolidasi antara pimpinan pusat dan daerah. Semakin jauh dari kesejahteraan dan perhatian semakin berpeluang daerah untuk memerdekakan diri. Wilayah itu meliputi kekuasaan Islam di Spanyol, kekuasaan Dinasti Mamalik di Mesir, dinasti kecil keturunan Bangsa Arab, keturunan Bangsa Persia, keturunan Bangsa Turki dan keturunan Bangsa Afrika. Badri Yatim, Sejarah Peradaban Islam Dirasah Islamiyah II (Jakarta: Raja Grafindo Persada, 2000), hlm. 129-145.

${ }^{3}$ Dalam sejarah Islam, dakwah Islam Muhammad SAW melakukan banyak perubahan bagi masyarakat Mekkah dan Madinah. Melalui misi tauhidullah, Muhammad SAW mengganti keimanan pada patung dan berhala menjadi beriman pada Allah SWT yang Esa, menghapuskan sistem kasta dan perbudakan, memuliakan derajat manusia. Muhammad SAW melaksanakan misi Islam dengan mengganti tradisi lama dengan tradisi baru, sebagai penyembah Allah SWT, mengimani ajaran Muhammad SAW, memerdekakan para budak dan melibatkan para wanita dengan berbagai kegiatan publik. Kondisi ini melampaui masa keemasannya setelah Muhammad SAW melaksanakan dakwah Islam di kota Madinah. Samsul Munir Amin, Sejarah Peradaban Islam (Jakarta: Amzah, 2010), hlm. 63.

${ }^{4}$ Wardi Bachtiar, Metodologi Penelitian Dakwah (Jakarta: Logos Wacana IImu, 1995), hlm. 25.

${ }^{5}$ Munzier Suparta (Ed.), Metode Dakwah (Jakarta: Rahmat Semesta, 2003).

${ }^{6}$ Jalaluddin Rakhmat, Psikologi Komunikasi (Bandung: Remaja Rosdakarya, 1999), hlm. 125.

${ }^{7}$ Tim Penyusun, Kamus Bahasa Indonesia, cet. IX (Jakarta: Balai Pustaka, 1986), hlm. 649.

${ }^{8}$ Bentuk-bentuk metode dakwah termaktub dalam QS. an-Nahl: 125, "Serulah manusia kepada jalan Tuhanmu dengan hikmah dan pelajaran yang baik dan bantahlah mereka dengan cara yang baik. Sesungguhnya Tuhanmu Dialah yang lebih mengetahui tentang siapa yang tersesat di jalan-Nya dan Dialah yang lebih mengetahui orang-orang yang mendapat petunjuk."

${ }^{9}$ Lihat, Munzir Suparta (Ed.) dkk., Metode Dakwah..., hlm. xvi.

${ }^{10}$ Satu kesuksesan kerajaan Islam Syafawi di Persia, adalah Khalifah Abbas I yang dikenal sebagai khalifah yang bijak yang tidak memaksakan kehendaknya untuk keyakinan aliran syiah menjadi aliran agama resmi negara. Memiliki kesabaran dan uswah hasanah yang mengantarkan syiah kuat di negara Persia/Iran. Dan sebaliknya, 
saat di bawah kekuasaan Islam, yang kerapkali memaksakan penduduk syafawi beraliran syiah mengantarkan pada konflik dan peperangan melawan kerajaan Turki Usmani. Oleh karena itu, toleransi pada perbedaan menjadi sebuah metode dakwah yang efektif. Fatah Syukur, Sejarah Peradaban Islam (Semarang: Pustaka Rezeki Putra, 2012), hlm. 39.

11 lbid., hlm. 40.

${ }^{12}$ Al-Qur'an adalah kalam Allah SWT yang diturunkan Allah SWT kepada Nabi Muhammad SAW melalui perantara malaikat jibril atau langsung diterima oleh Nabi Muhammad SAW. Al-Qur'an menjadi rujukan (referensi) dalam hidup dan kehidupan manusia. Melalui al-Qur'an, umat Islam akan terbimbing hidayah melalui jalan kebenaran. Oleh karena itu, al-Qur'an merupakan penjelas (bayan) dari segala kebingungan umat manusia dalam hidup dan kehidupan.

${ }^{13}$ Manna Khalil al-Qattan, Mabahis fii 'ulum al-Qur'an (Studi IImu-IImu Qur'an (terj) (Jakarta: Pustaka Litera Antarnusa, 2001), hlm. 35.

${ }^{14}$ Acep Hermawan, 'Ulumul Qur'an IImu untuk Memahami Wahyu (Bandung: Remaja Rosdakarya, 2013), hlm. 168.

${ }^{15}$ Jalaluddin Rakhmat, Psikologi Komunikasi, hlm. 67.

${ }^{16}$ Ahmad Mubarok, Psikologi Dakwah, hlm. 35.

${ }^{17}$ Kehidupan masyarakat Madinah saat Nabi Muhammad SAW memimpin, memiliki aturan yang bijaksana bagi kehidupan umat beragama. Kendati ia merupakan pemimpin agama dan sekaligus pemimpin negara, namun tetap memberi kebebasan kepada semua penganut agama untuk menjalankan agama sesuai dengan keyakinan tanpa ada gangguan dan ancaman. Menciptakan ukhuwah insaniyah kepada semua masyarakat Madinah, ukhuwah islamiyah kepada kaum Anshar dan Muhajirin, mendirikan masjid. Dengan demikian, kehidupan masyarakat Madinah menjadi masyarakat yang beradab.

18 Penjajahan nagara-nagara Barat kepada beberapa negara Asia termasuk Indonesia membangkitkan persatuan dan kesatuan tokoh-tokoh muslim Indonesia. Melalui kekuatan raja-raja Islam Nusantara; Kerajaan Islam Demak, Kerajaan Islam Samudra Pasai, dan Kerajaan Islam Banjar, kekuatan muslim dapat terkordinasi dengan baik. Perjuangan Islam juga dilanjutkan oleh beberapa kiai dan santri pesantren yang antipati pada imperialisme Barat.

${ }^{19}$ Amar ma'ruf nahyi munkar adalah perintah melakukan kebaikan dan mencegah kemunkaran. Hukum melaksanakannya fardu kifayah, seperti dalam QS. al-Imran: 104, "Hendaknya ada sekelompok kaum yang mengajak kepada kebaikan dan mencegah kemunkaran. Artinya, melakukan amar ma'ruf nahyi munkar tidak semua umat manusia (muslim) untuk melakukannya (syiar kepada masyarakat lain) karena memerlukan syarat dan kemampuan. Syarat dan kemampuan itu misalnya harus memiliki good will, good ethos, dan good moral character. Dalam pendapat lain, melaksanakan amar ma'ruf nahyi munkar adalah fardlu a'in, artinya setiap muslim harus melakukannya bagi diri dan keluarganya agar tidak masuk neraka (quu anfusikum wa ahlikum naar).

${ }^{20}$ Abdul Muthalib memiliki anak: Abdullah, Abdul Ka'bah, Abu Lahab, Zubair, Abi Tholib, Dirar, Haris, Hujal, Abbas, Hamzah, Qusam.

${ }^{21}$ Hasyim memiliki anak: hanya satu Abdullah.

22 Silsilah suku Quraisy dan Nabi Muhammad SAW, adalah Nabi Ibrahim AS, Nabi Ismail AS, Ghalib, Lu'ay, Ka'ab, Murrah, Kilab, Qusay, Abdul Manaf, Hasyim (buyut), 
Abdul Muthalib (kakek), Abdullah (ayah), Muhammad, Qasim dan Ruqoyah.

${ }^{23}$ Kebiasaan orang Arab, setiap bayi lahir akan disusukan oleh seorang ibu kampung guna mendapatkan udara kampung yang segar. Dengan memberikan upah maka Nabi Muhammad mendapat pengasuhan dari Halimah as-Sadiyah. Ada banyak keanehan setelah mengasuh Muhammad, diceritakan bahwa kehadiran Muhammad SAW dalam keluarga yang miskin itu sungguh membawa berkah. Kehidupan rumah tangga Haris dan Halimah yang sebelumnya suram dan penuh kesedihan karena miskin, berubah menjadi bahagia penuh kedamaian. Kambing yang mereka pelihara menjadi gemuk-gemuk dan menghasilkan lebih banyak susu dari biasanya. Rumput yang digunakan sebagai tempat menggembala domba juga tumbuh subur. Mereka percaya betul bahwa anak dari Mekkah yang mereka asuh itulah yang membawa berkah dalam kehidupan mereka. Ensiklopedi Islam (Jakarta: PT Ichtiar Baru Van Hoeve, 1994), hlm. 261.

${ }^{24}$ Pada hari setelah kelahiran, Abdul Muthalib langsung datang ke rumah Aminah setelah mendengar kabar gembira itu. Diangkatnya cucunya yang tampan itu, diciumnya, didekapnya dengan mesra. Lalu dibawanya berlari-lari menuju Ka'bah. la thawaf (haji) mengelilingi Ka'bah sambil menggendong bayi itu. Seminggu kemudian Abdul Muthalib mengadakan selamatan. Semua orang Quraisy diundang dan mereka pun hadir untuk menyatakan turut bergembira. Pada saat itulah Abdul Muthalib memberikan nama Muhmmad kepada cucunya itu, yang artinya orang yang terpuji. Nama itu agak ganjil. Oleh karena itu, mereka berkata: "Sungguh di luar kebiasaan, keluarga Tuan begitu besar, tetapi tak satupun yang diberi nama demikian. Abdul Muthalib menjawab: "Saya mengerti. Dia ini memang lain dari yang lain. dengan nama ini saya ingin agar seluruh dunia memujinya."

${ }^{25}$ Pada saat perselisihan antara Abu Umayyah bin Mughiroh dari suku Makzum, mengenai peletakan Hajar Aswad. Sebagai orang yang tertua, tampil ke depan dan berkata: "Serahkanlah putusan kamu ini kepada orang yang pertama sekali memasuki pintu Shofa ini." Semua kepala suku menyetujui usul tersebut. Semua menanti siapa yang mula-mula masuk melalui pintu itu. Kemudian tampaklah Muhammad SAW muncul dari sana. Semua hadirin berseru: itu al-Amin, orang yang dapat dipercaya. Kami rela menerima keputusannya." Ensiklopedi Islam (Jakarta: PT Ichtiar Baru Van Hoeve, 1994), hlm. 262.

${ }^{26}$ Pada usianya yang kedua puluh lima, atas permintaan Khadijah binti Khuwalid, seorang saudagar kaya-raya, Muhammad SAW berangkat ke Suriah membawa barang dagangan saudagar wanita yang telah lama menjada. la dibantu oleh Maysarah seorang pembantunya yang telah lama bekerja pada Khadijah. Sejak pertemuan pertama dengan Muhammad SAW, Khadijah menaruh simpati melihat penampilan Muhammad SAW yang tampan dan santun. Kekagumannya bertambah setelah mengetahui bahwa hasil yang dicapainya di Suriah.

${ }^{27}$ Ensiklopedi Islam (Jakarta: PT Ichtiar Baru Van Hoeve, 1994), Hal. 259.

${ }^{28}$ Ibid., hlm. 260.

${ }^{29} \mathrm{lbid}$.

${ }^{30}$ Status sebagai nabi dan rasul tidak bisa diusahakan oleh siapa pun. Jika seseorang misalnya menghabiskan seluruh waktunya untuk beribadah dan meninggalkan segala macam kesenangan dunia dengan harapan mudah-mudahan diangkat menjadi nabi tentu harapan itu akan sia-sia. Yunahar Ilyas, Kuliah Aqidah Islam (Yogyakarta: 
LPII, 2007), hlm. 134.

${ }^{31}$ Ibid., hlm. 135.

32 Ibid.

${ }^{33}$ Ibid.

${ }^{34}$ Arti jahiliyah adalah zaman kebodohan, kegelapan, tidak adanya sinar hidayah yang menuntun pada nilai-nilai keindahan. Lawan dari jahiliyah adalah berperadaban, indah dan tidak tampak perilaku yang menyimpang dalam ukuran nilai, norma sosial dan agama. Saat zaman jahiliyah, terjadi perbudakan, diskriminasi, ketidakdilan, dan acapkali tidak mengenal baik dan buruk, semua berdasarkan nafsu dan kepentingan dunia.

${ }^{35}$ Ahli kitab adalah kaum yang memiliki kitab suci. Secara khusus istilah ahli kitab dipakai untuk menyebut para penganut agama sebelum datangnya agama Islam. Bagi mereka telah diturunkan kitab-kitab suci seperti: Injil, Taurat, dan Zabur, yang diwahyukan kepada para rasul atau nabi. Namun para penganut agama yang dimaksud, lebih tampak tertuju kepada kaum Yahudi dan Nasrani. Jumhur (mayoritas) ulama sepakat dua penganut agama inilah yang dinyatakan sebagai ahlul kitab. Lihat Ensiklopedi Islam (Jakarta: PT Ichtiar Baru Van Hoeve, 1994), hlm. 77. Hal ini disampaikan oleh seorang Pendeta Buhairoh yang mengutarakan pesannya kepada Ali bin Abi Thalib, agar menjaga keberadaan Muhammad yang kelak akan menjadi rasul dan ditunggu oleh seluruh umat manusia, "Saya berharap Tuan berhati-hati benar menjaga dia." Usahakan agar hal ini jangan diketahui oleh orang-orang Yahudi. Mereka telah membunuh nabi-nabi sebelumnya. Ensiklopedi Islam (Jakarta: PT Ichtiar Baru Van Hoeve, 1994), hlm. 262.

${ }^{36}$ Badri Yatim, Sejarah Peradaban Islam, hlm. 87.

${ }^{37}$ Secara etimologis (lughat), aqidah berakar dari kata 'aqada, ya'qidu-'aqdan, 'aqidatan. 'aqdan, berarti simpul, ikatan, perjanjian, dan kokoh. Setelah terbentuk menjadi 'aqidah berarti keyakinan. Relevansi antara 'aqidah dan 'aqdan adalah keyakinan itu tersimpul dengan kokoh di dalam hati, mengikat, dan mengandung perjanjian.

${ }^{38}$ Samsul Munir Amin, Sejarah Peradaban Islam, hlm. 350

${ }^{39}$ Nalar Islam Nusantara, Studi Islam ala Muhammadiyah. Al-Irsyad, Persis dan NU (Jakarta: Departemen Agama Republik Indonesia Direktorat Jenderal Pendidikan Islam Direktorat Pendidikan Tinggi Islam, 2007).

\section{DAFTAR PUSTAKA}

Al-Qattan, Manna Khalil. 2001. Mabahis fii ‘Ulum al-Qur’an (Studi IImu-IImu Qur’an (terj). Jakarta: Pustaka Litera Antarnusa.

Amin, Samsul Munir. 2010. Sejarah Peradaban Islam. Jakarta: AmzahBachtiar. Wardi. 1995. Metodologi Penelitian Dakwah. Jakarta: Logos Wacana IImu. Dasuki, Hafizh dkk. 1994. Ensiklopedi Islam. Jakarta: PT Ichtiar Baru Van Hoeve. Ilyas, Yunahar. 2007. Kuliah Aqidah Islam. Yogyakarta: LPII.

Hermawan, Acep. 2013. 'Ulumul Qur'an Ilmu untuk Memahami Wahyu, Bandung: Remaja Rosdakarya.

Rakhmat, Jalaluddin. 1999. Psikologi Komunikasi. Bandung: Remaja Rosdakarya. 
Enung Asmaya: Implementasi Metodologi Dakwah Islam Nabi Muhammad SAW di Indonesia

Suparta, Munzir (Ed.). 2003. Metode Dakwah. Jakarta: Rahmat Semesta.

Syukur, Fatah. 2012. Sejarah Peradaban Islam. Semarang: Pustaka Rezeki Putra. Tim Penyusun. 1986. Kamus Bahasa Indonesia, cet.IX. Jakarta: Balai Pustaka.

Tim Penyusun. 2007. Nalar Islam Nusantara, Studi Islam ala Muhammadiyah. Al-Irsyad, Persis dan NU. Jakarta: Departemen Agama Republik Indonesia Direktorat Jenderal Pendidikan Islam Direktorat Pendidikan Tinggi Islam.

Yatim, Badri. 2000. Sejarah Peradaban Islam Dirasah Islamiyah II. Jakarta: Raja Grafindo Persada. 